\title{
The application of new technologies to remote interpreting
}

\author{
Tim Connell \\ City University London
}

Changes in language needs and language policies have had an impact on the provision of services which require access to interpreting. It is perhaps inevitable that new professional areas such as community interpreting $^{l}$ should look to new technologies in the search for solutions to particular problems or (on a more positive note) to provide more efficient services. This article suggests that there is ample scope for the extension of such services by the application of new technologies. Such a process will, however, have an impact on both the practical and ethical aspects of the interpreter's work.

\section{Introduction}

Remote interpreting is not a recent phenomenon (Moser-Mercer 2003). Experiments in remote interpreting began in the 1970s and have continued to the present day with varying success. Both UNESCO and the EU have been involved in experiments, and more recently the International Telecommunication Union has been involved in projects with the University of Geneva. ${ }^{2}$ Australia has a full-scale telephone interpreting service, the TIS $^{3}$, funded at federal level, which dates back to 1973. So do other countries, such as South Africa with its eleven official languages. ${ }^{4}$

Commercial services using satellite technology, based particularly in the USA, have been active for a long time and in recent years have begun to establish themselves in other countries, either by merger and acquisition or as start-up activities.

In recent years there has been massive growth not only in the demand for interpreting, but also the types of interpreting that are needed Holly Mikkelson has listed over a dozen. ${ }^{5}$ Factors such as distance, security, access to less used languages and cost have all contributed to the growth of modes of delivery that take advantage of the latest developments in technology, ranging from conference calls to video link-ups. Satellite communications have also led to the proliferation of international service providers, and new types of technology open different possibilities. Mouzourakis (1996), for example, breaks videoconferencing down into a number of activities: videophony (or videotelephony) where a facial image is transmitted with a telephone call; whiteboarding, where documents are exchanged by computer and commented upon; desktop videoconferencing, using a camera attached to PCs; and studio or room videoconferencing, where two or more studios can be linked up by video or audio. 
All of this raises interesting questions with regard to the provision of proper levels of service and ensuring that both clients and end-users receive an equivalent level of support to what they would receive in remote interpreting if traditional face-to-face interpreting were available. In the area of conference interpreting, the expansion of the EU, and the cost of providing multi-lingual interpreting services for international meetings or other organisations such as the UN, has led to research into other aspects of such activities, including wear and tear on the interpreters themselves, and whether remote provision can provide equivalent standards of quality (Moser-Mercer 2005a). Ko (2006) has also rightly raised the question and potential of using distance methods for both training and continuous professional development.

The major impact of remote interpreting, however, can be seen most clearly in the public services. The way has been led, logically enough, by organisations offering sign language interpreting by video link. The recognition of interpreting services as an important element within public services such as health, local government and the law has created an alltoo-often urgent need to set up and maintain a proper interpreting service. The emphasis has been on face-to-face liaison interpreting, either in 1:1 situations ranging from doctors' surgeries to police stations, or in the more formal context of tribunals or courts of law. Problems encountered range from the purely logistical and financial through to the question of locating suitably qualified interpreters in a particular language in a specific geographical area. The need and demand for interpreting services has arisen in recent years as a logical consequence of globalisation, changes in international legislation with regard to human rights, and the massive increase in population movements around the globe. Changes as a consequence of political events such as the break-up of the USSR have led to the re-emergence of languages that had not been used to any extent in the international arena for several generations. The gradual realisation that it is important to recognise the importance of the languages that other people speak (let alone their linguistic preferences) is a process which has received significant impetus from EU language policies and can have serious implications in terms of government policy and the response of organisations that have to deal with the general public.

All this means that even countries with a history of widespread immigration can find themselves receiving communities with no historical connection to that country (and hence no established community to help them settle), so that there is a pressing need for support in languages which are not widely spoken and rarely studied. Procedures such as the dispersal of asylum seekers from the capital city to provincial towns (as has happened in the case of London) can exacerbate the situation and create additional pressure on local services. It is not surprising therefore that remote interpreting should come to be seen as part of the solution as policy makers and managers will inevitably wish to explore any avenue that could deliver a cheaper interpreting service. However, it will be seen that this also 
gives rise to a number of problems and concerns, ranging from the cost of provision to questions of quality assurance and accountability.

\section{Current situation and developments}

An increasing number of government services and public service providers in the UK have signed up with American companies for a variety of services which may include translation and face-to-face as well as telephone interpreting. A random search on the Internet will throw up a large number of service providers, many of whom will include public service areas as part of a wider range of provision as diverse as voice-over and cultural briefings. Kwintessential offers interpreting as only one of a wide range of language-related activities. These include editing and proofreading, crosscultural courses, on-line language tuition and recruitment services. It also provides useful supplementary information with lists of articles on subjects related to their many language activities and there is a handy ten-point list on how to work with an interpreter. ${ }^{6}$ The Bridge-World Language Center Inc. offers community interpreting within its range of activities, and for the client it provides training courses on how to work with interpreters. New interpreters have to attend an orientation programme and pass an oral screening besides a test on a Code of Ethics. Whose is not specified, but the logo of the American Translators Association is displayed on the front screen.

This placing of community interpreting within a number of services indicates that to a great extent the same concerns arise in remote interpreting as in other language activities. Interpreters will still have to focus on the traditional concerns of consistency, cohesion, completeness of interpretation, fluency of delivery, correct grammatical usage, native accent, and a pleasant voice (Kahane 2000). Quality and efficiency will always be paramount. But a number of new factors intrude and ways have to be found of resolving them.

\section{Procedures and issues}

Faced with new technologies, new practices and new methods of working, there has inevitably been some resistance from interpreters. Many of their concerns appear to be justified and solutions will need to be found, arising from the oral and immediate nature of the exercise. Traditionally, the interpreter expects to see the speakers. This is evidently not possible over the telephone (although videophone has scope for development here) and there can be practical difficulties with videoconferencing and link-ups. Nonverbal cues constitute a very high percentage of communication in normal speech. The interpreter may therefore not be able to gauge facial expression, irony, emotion or the response to the message in either direction. Difficulties may be encountered with the technology. Interpreters complain that the screen may glitter or be less than sharp; the camera may not be pointing 
at a given moment in the right direction, or someone could move their chair and go out of shot for a key moment. The interpreter may not be in contact with camera, sound crew or producer, and there may be no opportunity for querying or repeating questions. In a conference environment, there may be references to a screen or display board which is out of sight for the interpreter. For both sound and vision, conditions may be cramped and below the accepted norms and there is concern that interpreters will suffer from burn-out more quickly than in conventional situations. (Moser-Mercer 2005b)

A number of key organisations, including AIIC and $\mathrm{JISC}^{7}$, have combined to produce a code of practice. They insist that the interpreters must be consulted over both feasibility and detailed planning, and should also have access to the same information as delegates at the meeting, which may require full connectivity with both computer and video screens. They specify international standards which must be complied with: ISO 2603; ISO 4043 and CEI 60914. These cover aspects such as sound quality, picture definition and health factors such as screen breaks, working in artificial light and a possibly stressful environment. Tele-interpreting is deemed to be unacceptable. ${ }^{8}$ Two hours per day is the recommended maximum working time, though the guidelines produced in 2003 concede that three hours is acceptable. (AIICb January 2003.)

Clearly these codes are directed principally towards conference interpreting, but there is no way of saying which mode of remote interpreting is going to be used in a public service context. Sign language interpreting, for example, could benefit from a more widely available service using videoconferencing or video link facilities. And the same factors still apply, ranging from the impact on the interpreting process of not being a direct part of the proceedings to health and safety factors for the interpreter, which might include the lack of proper ventilation and light or matters such as having to work anti-social hours. The latter may prove to be a key factor in the provision of interpreting facilities by satellite as a consequence of working across time zones. Sheer distance is another factor that needs to be taken into account, plus the needs of remote communities.

Again, the questions that arise are not exclusive to the introduction of new technology in the context of interpreting. There is ample scope for the development of teleworking for interpreters as well as translators who are quite accustomed nowadays to producing the bulk of their work on-line with the fax as a back-up for clients who may well not be in the same country. This, however, is also a fairly new system of working and the ramifications need to be considered. There are benefits to all parties individuals, employers and society as a whole. Less time and money is spent on commuting; it is possibly easier to fit work in with family commitments; there are no geographical limitations (which includes hazardous travel in mid-winter); individuals can create their own working environment and this could make life easier for the disabled; there are benefits to independent working away from an office environment. Set against all that, individuals could find themselves isolated with impacts 
ranging from the quality of social life to the ability to negotiate better terms with their employer; hours, although more flexible, could also be anti-social (though this may be a factor when providing 24-hour cover for health or emergency services, for example); it can be difficult to concentrate at home, and there may be health and safety factors which would not be permitted in the workplace. For employers, office space is reduced, it may be possible to get staff to work more flexibly, and work can be transferred to areas which are remote and where regional authorities may even offer incentives for job creation. However, setting-up and running costs can be higher as there are fewer chances of sharing facilities or some equipment; IT support may be a problem; and there is less control over elements such as enforcing company procedures or guaranteeing confidentiality or security. Social benefits include work-life balance, supporting communities and reducing pressure on such facilities as public travel. ${ }^{9}$

\subsection{Interpreter service provider issues}

The above items are by no means exclusive to interpreting, but they include factors that any service provider will need to take into account if setting up remote provision. And there may be incentives to do so. It could be possible to pay people a retainer to be available on duty, but pay them a full rate only for calls that they take. It would be possible to reduce the number of staff interpreters by directing less used languages either to a teleworker or even by satellite link to the country of origin. It would be easier to provide for out-of-hours cover without having to maintain expensive offices. As the development of new technology becomes more sophisticated and as costs fall (Broadband is a case in point) the efficiency of the service is likely to improve.

\subsection{Service commissioning issues}

For the people who require the interpreter service, quality and reliability must be a key issue. There is something fixed about an organisation with a set of offices and a nameplate outside a building. Being assured of the quality of provision by staff who are in the next county is rather more difficult, and could become even more so if those staff are not even in the same country. Issues can then arise in case of disputes over legal jurisdiction and where liability can be placed if things go wrong. Recording telephone interpreted sessions can be a way to monitor and keep records but has to be secure. There may also be questions over acceptable standards or the relevance of training or experience if the interpreter who is being contacted belongs to a professional body in their own country which offers a different set of codes of conduct or guidelines to good practice. On the other hand, there are the benefits mentioned above of the range of languages, the times 
at which services can be offered, and savings could be a factor to add to flexibility.

\subsection{Service user issues}

For the service user, there is the additional question of knowing precisely what's on offer as well as who precisely is offering it. In the case of the Lothian Out-of-Hours Service, there is a note on the website that NHS24 has access to interpreting services for over 100 languages but the telephone number is not given and the flowchart showing how the system works omits any reference to interpreters. ${ }^{10}$ Apart from the matter of cost (and knowing who precisely is going to pay for the service) ${ }^{11}$ there may well be the need for additional assurances on confidentiality and quality. If the service provider is a commercial company, there is also the possibility that they could be taken over by another organisation which does not offer the same quality or it might go out of business altogether.

\subsection{Service delivery issues}

Apart from the question of the credit status of the service provider, there is the broader quality issue of who is providing what and to whose standard. It is striking that in the speed of development over the last ten to fifteen years there has been a rapid growth in the number of associations offering a range of membership services to interpreters. ${ }^{12}$ Some may be international and have chapters in more than one country. Others may be at country level, but may also be found at regional and even county level (that is counties of US size). Some only focus on part of an American state, such as North-East Ohio. A significant number of these relate to sign language interpreting and of course there are membership bodies with a specialist slant, such as Euskal Itzultzaile, Zuzentzaile eta Interpretarien Elkartea, which covers Basque. Some organisations cover one particular skill (typically translation or conference interpreting) whilst others cover a larger number of language activities including things like voice-over or localization. Whilst it is important for practitioners to have support to which they can have access, it is perhaps unfortunate that the level of provision is often quite so diverse. This leads to a danger of it being either fragmented or unable to present a united front when dealing with other large organisations, such as multi-national companies or European community institutions, let alone when negotiating with governments.

\section{Quality assurance procedures}

The other major issue which derives from the fragmentation of professional activities is quality assurance. A significant number of organisations, in- 
cluding commercial firms and small-scale providers of local services, will publish information on their quality assurance procedures. Some of these are quite bland, stating that these are in place or are taken seriously by the organisations; others are more detailed. It is common to state that quality control is rigorous and ongoing (even though specifics rarely follow). Many companies have their own recruitment process which includes an assessment test. Some, like Bridge-World, will refer to membership of professional bodies, and others will indicate broadly the kind of procedures that are followed. This may or may not include specific reference to customer participation. By way of illustration, Language Line is a major provider for public services. It offers 150 language combinations and will also provide an over-the-phone service for limited-English-speaking customers. It will screen new interpreters and carry out in-house language audits. ${ }^{13}$ The website assures customers that interpreters are professionally trained and tested. In practice this means that most of them will be graduates and should have a relevant post-graduate qualification, such as the Diploma in Public Service Interpreting. Staff must also pass internal assessments which are externally validated. Language Service Associates claim to be pioneers in telephonic interpreting and offer a 24-hour service. Quality Assurance appears on the front page of their website, but only assures potential users that quality is a number one priority, and that they recruit top staff. Linguists are trained, tested and re-evaluated as part of the process. However, it is unusual for any company to specify precisely what qualifications they look for in staff, or to give details of the kind of training that staff undertake. ${ }^{14}$ Similar assurances are given by most of the sites that have been visited.

It is refreshing how often it is stated that a bi-lingual person does not necessarily make a good interpreter, and there is a general awareness that people will have a different range of specialisation, although one Chinese website does rather hopefully offer a full range of service from conference activities through to visiting the local shopping mall to get a guaranteed good price. Interpreting seems to be at a slight disadvantage in that there are more opportunities for translating to be tested. Apparently there is no single certification process for interpreters in the USA, but that may simply be a reflection of the federal structure of that country. ${ }^{15}$ There has undoubtedly been a proliferation of tests, registers and standards in different countries, which gives rise to concerns about levels and equivalences, not only when people move across borders but also when organisations offer services worldwide. There are, however, some key examples, such as NAJIT (The National Association of Judiciary Interpreters and Translators) in the USA, ${ }^{16}$ NAATI (National Accreditation Authority for Translators \& Interpreter) in Australia, ${ }^{17}$ and the Chartered Institute of Linguists in the UK. Masters' degrees in language skills are on the increase in the UK, but most of these are in translation rather than interpreting, and tend to be based on academic rather than professional or vocational criteria. 


\section{Codes of ethics}

There tends to be an overlap between quality assurance procedures and statements regarding codes of conduct, practice, responsibility or standards versus guides to good practice or just plain guidelines. (Bancroft 2005) ${ }^{18}$ Terms of business, whilst covering specifics such as dates for payment, also tend to touch on matters of proper procedure and what can be considered as acceptable (and indeed unacceptable) behaviour. Some codes take an unequivocal moral stance: "Do no harm" (...) "Strive to do good". ${ }^{19}$ It should be noted that items such as confidentiality may then appear in the Guidelines for Professional Practice, whereas such a central requirement for interpreters ought to appear in the code.

Although translation and interpreting tend to be separated out (and sometimes the different types of interpreting as well) no code of ethics seen to date refers specifically to remote interpreting. At-sight translation (traduction à vue, which may concern health or court interpreters) does not figure either, although a section will appear in the forthcoming updated version of the Code of Professional Conduct of the Chartered Institute of Linguists in London. However, consideration does need to be given to remote interpreting, given that it will involve different methods of working (no verbal cues, different physical location, reliance on technology for communication to be maintained, etc.) and may well operate across borders.

In such circumstances, more global features will need to be taken into account, such as local legislation, since commercial and statecontrolled providers may operate under different terms of reference. The professional standing of interpreters may vary between countries, the dangers run by interpreters in Iraq and other war zones being a case in point. ${ }^{20}$ Interpreting may even appear as a sub-set of another professional group - one translating and interpreting body in the USA is actually affiliated to the Newspaper Guild-Communications Workers of America. ${ }^{21}$ Standard procedures for registration and annual operating may also vary. Then there are variants in what is considered to be proper practice. In Britain any gift beyond a box of chocolates may be viewed with suspicion, and interpreters are expressly forbidden to accept gifts of any sort in order to avoid any charge at a later date of collusion or improper behaviour. In other countries, gift-giving is perfectly normal and not considered to be evidence of malpractice. So cultural sensitivity and respect for local practice need to be worked in somehow. Courteous forms of address and standard honorifics may be a case in point for a telephone interpreter where the rather brusque enquiries which pass off as normal in one society could cause serious offence in another. And there are terms which may not exist in one legal system but which are crucial to an understanding of another: "remand", "suspended sentence", "probation" and "release on licence" may all need to be paraphrased when moving out of the context of UK Law.

Any guide to good practice for remote interpreting will need to take into account the specific means of establishing contact between parties. It will be important not to dial the wrong number; the right person must be 
available at the other end of the phone; time zones must be taken into account, etc.. Therefore, procedures in standard interpreting may need to be amended.

- How is the interpreter to be briefed about the topic of the call?

- What preparation time will the interpreter have?

- What needs to be done about acronyms, job titles of individuals or other items specific to a particular call?

- Will the interpreter have the chance to speak briefly to the client to make sure that they speak the same variety of a particular language?

- How to deal politely with interruptions?

- How to stop the flow of conversation in order to double-check a date or a figure?

- How to ensure that the parties have really understood the message if the interpreter cannot see how it has been received?

- What to do about a pause where someone is considering their response, as opposed to a gap as no-one knows quite whose turn it is to speak next?

- How to deal with cultures that have varying views on turn-taking?

- How to deal with emotions ranging from bewilderment to rage?

All of this may be taking place with people fully aware that they are being charged by the second for the service, which may also make them unduly nervous. And the distance environment will also have other spin-offs: the interpreter might feel more secure than would be the case in a courtroom with irate family members in the public gallery. On the other hand, can the service provider guarantee that the line is electronically secure?

\section{Identifying and measuring good practice}

Again, it is necessary to separate out what is considered to be good practice in community interpreting from what may be taken as a benchmark or beacon in this novel area for other organisations to follow. There are a number of areas where equal opportunity may be enhanced (and this is a key area of legislation in the UK). A service provider may be able to provide an interpreter in a rare language by using the phone; remand cases can be dealt with more quickly by video link if time is not lost moving the prisoner between prison and court.

But pitfalls abound. In 2005 the Board of Directors of the National Association of Judiciary Interpreters and Translators (NAJIT) in Texas wrote to the governor to protest against House Bill 1642, which was intended to authorise counties with a population of over 50,000 people not to use a licensed interpreter if one was not available within a distance of 75 miles. ${ }^{22}$ In countries where populations can be sparse, distances enormous and winters unkind, there would seem to be ample scope for the use of interpreters by telephone or video link. 
It may of course be premature to be looking for examples of good practice in an area of professional endeavour which has only been recently established, and which is in a constant state of development given current technological advances. However, professional bodies should be able to pick up on situations encountered by their members, and the example above shows how an alert organisation can exert pressure to ensure that fair procedures are followed. There is perhaps a difficulty in that only those interpreters that wish to adhere to a code of conduct will actually join the organisation and so it may be difficult to identify easily areas where procedures are inadequate. Individual interpreters, without offending their own codes of confidentiality of course, may also be able to reflect on what they see. And even if they are not able to act on procedures which are less than perfect, they may well be able to contribute by praising examples of good practice which can be disseminated by the many discussion groups that exist on-line. It is also possible to scan the websites of the growing number of organisations that offer language services. It can only be said, however, that mistakes in the English on some of those websites will not inspire customer confidence!

\section{Training \& Assessment}

In a perceptive article, Holly Mikkelson looks at the emergence of a profession and the gradual professionalisation of a given area, identified by an initial element of disorder as the need for a service emerges and individuals respond to a particular need in the absence of any formal organisation. This is marked by an absence of quality control, low wage rates and hence an ambiguous view on the part of other professionals of that particular activity. Over a period of time, formal training emerges though neither practitioners nor service providers have a great deal of incentive to make use of it, as the former resents the cost in terms of time and money, and the latter would bluntly prefer to employ unqualified occasional staff in order to save money. A period of consolidation, led by the emergence of professional bodies, will follow, and at this stage codes of conduct and a formal set of standards will emerge. (Mikkelson 2004: 1-4.)

Probably the longest-established awarding body for interpreting is the National Accreditation Authority for Translators and Interpreters, which was established in $1977 .{ }^{23}$ It offers accreditation from paraprofessional interpreter through to conference interpreter (senior) and maintains a register.

In the UK, the Certificate in Public Service Interpreting of the Institute of Linguists became a Diploma, was recognised by the government through the Qualifications and Curriculum Authority and established at Level 6 in the National Qualifications Framework, placing it in level at honours degree standard. ${ }^{24}$ This is used at national level and is the main gateway to the National Register of Public Service Interpreters. 
Private companies frequently state on their websites that they only use qualified and experienced interpreters, without necessarily defining what this means. Reference is often made to membership of professional bodies. Some do screen their interpreters through tests on such things as codes of ethics and conduct oral tests and arrange for re-evaluation year on year. One (Language Line) has gone so far as to set up its own University (presumably along American corporate lines of the sort which is just beginning to appear in the UK). It offers to test and train bi-lingual staff to be better interpreters, and evaluate freelancers' knowledge of professional ethics, interpreting protocols and industry terminology. (Telephone interpreting is mentioned specifically on the site. ${ }^{25}$ The extent to which language companies refer to quality and training procedures is re-assuring. However, evidence based on objective and measurable criteria will also be needed, not only in terms of linguistic competence but also knowledge of the domain. As international suppliers become more commonplace, evidence of familiarity with local structures and procedures will also be required. Methods need to be established in order for individuals to be vetted for security or criminal records, quite possibly in more than one jurisdiction.

As borders become increasingly meaningless, the need will emerge for objective portable external criteria which are recognised by the international community. As more people travel, and national communities (like the British in Aquitaine or the Germans in Mallorca) become more established in the country of their choice, so expectation will be for recognisable standards to emerge in the treatment of them by the services which they are entitled to expect, for example, under EU legislation.

\section{Further developments}

The high speed of development in technology is inevitably going to have an impact on all walks of professional life, and interpreting is no exception. Other processes taking place (like the outsourcing of translators from the $\mathrm{EU}$ and recent suggestions of the same at the UN) are indicative of new ways of viewing the provision of services which are clearly essential and yet which constitute an increasing proportion of many public budgets.

Interpreting on the Internet is quite feasible and a button for interpreting alongside the one for translation is now a distinct possibility (although the sometimes erratic output of automated translation is something of a warning to check that the output is of sufficient quality and fit for purpose). Chat Interpreting is already with us: Today Translations (appropriately enough) offers interpreting via instant messaging systems such as MSN Messenger. ${ }^{26}$ Interpreting linked to activities on the Internet has been tried in Canada via the webcasting of conferences or linking language services to a previously recorded conference. Interpreting support can be added via a telephone link which will be free if set up by computer (Selhi 2000). 
It is probably only a matter of time before mobile phones can be used for interpreting for both sight and sound. But the needs of the end users are paramount. New technology already offers opportunities for supporting minority languages and sign language with its reliance on a visual prompt. There is no doubt that major changes lie ahead and the standing of the whole languages profession could be enhanced if its members are seen to keep up with the speed of change and then harness it for the good of the people they serve. Quality is vital and ways need to be investigated to see how the high standards achieved elsewhere by the profession can be maintained in the face of new challenges. It should be noted, however, that research in this area can be difficult because of confidentiality, commercial for the companies on the one hand, and ethical for the interpreters on the other. Even so, the speed of development in the technology calls for additional research into how services can best be provided, especially in those areas where the more traditional modes of delivery are inappropriate or prohibitively expensive. There is scope for additional work looking at the impact that these new methods of working will have not only on the training of interpreters but also on ways in which working practices will have to change in terms of accuracy and efficiency, let alone health and safety. Any such research needs to include a wide variety of stakeholders, ranging from the designers of the technology through to the service providers and users, not to mention the interpreters who will have to absorb and respond with their customary dedication and professionalism to major changes in their future working lives.

\section{Conclusion}

In some respects, the needs of remote interpreting are no different from those of any other form of interpreting. However, current practice needs to be evaluated against the quality standards, mission statements and codes of practice which abound. Common areas of interest need to be identified, perhaps with funding from international bodies, and common standards fixed. Ways have to be found to ensure that best practice becomes the norm. Academic institutions, professional bodies, service providers and individuals all have a role to play.

Finally, it is worth noting the mission statement drawn up by the China Satellite Communications Corporation, which offers a satellite interpreting service between Chinese and English, French, Japanese plus other languages:

In the face of intensifying competition both at home and from abroad, our mission is to be more strenuous and work more arduously, adhering to the principle of "Two Highs \& Four News"(namely high starting point, high positioning; new mode, new operation, new product and new management). We will carry out the spirit of laborious work, and cooperate 


\section{widely and honestly with our friends to build a brilliant satel- lite communications enterprise. ${ }^{27}$}

We could all do worse than that.

\section{Bibliography}

AIIC (2000). Code for the use of new technologies in conference interpretation. www.aiic.net.

AIIC Technical and Health Committee (2003). Guidelines for remote conferencing. www.aiic.net.

Bancroft, Marjory, (2005). The Interpreter's World Tour (an environmental scan of standards of practice for interpreters). Maryland: National Council on Interpreting in Health Care.

Fors, Jenny (2006). Perspectives on remote public service interpreting. On line at: http://lisa.tolk.su.se/remote-fors.html

Gile, Daniel (1995). Basic Concepts and Models for Interpreter and Translator Training. Amsterdam/Philadelphia: John Benjamins.

Gile, Daniel (1999). "Assessing the pros and cons of remote interpreting: comments and future prospects from a research perspective". Alberto Alvarez Lugris \& Anxo Fernandez Ocampo (eds). Anovar/anosar estudios de tranduccion e interpretacio. Vigo : Servicio de Publicacion da Universidade de Vigo, vol. i, 119-121.

Heh, Yung-Chung \& Qian, Hu (1997). "Over-the-Phone Interpretation: A New Way of Communication Between Speech Communities". Muriel Jérôme-O'Keefe (ed.). Proceedings of the 38th Annual Conference of the American Translators Association. Alexandria, VA: American Translators Association, 51-62.

International Telecommunication Union (2001). Final report of first test of remote interpreting. Evaluation of human factors and stress parameters. Joint project ITU, ETI, Swisscom New Technologies. IAMLAPD/2001/R.8. Geneva: International Telecommunication Union.

Kahane, Eduardo (2000). Thoughts on the quality of interpretation. On line at: www.aiic.net

Ko, Leong (2006). "Teaching interpreting by distance mode: ossibilities and constraints". Interpreting 8(1), 67-96.

Ko, Leong (2004). Teaching interpreting by distance mode. $\mathrm{PhD}$ thesis. University of Queensland.

Mikkelson, Holly, (1996). "Community interpreting: an emerging profession". Interpreting 1(1), $125-129 .{ }^{28}$

Moser-Mercer, Barbara (2003), Remote Interpreting: Assessment of human factors and performance parameters. On line at: www.aiic.net

Moser-Mercer, Barbara (2005). "Remote Interpreting: the crucial role of presence". Bulletin Suisse de Linguistique Appliqué 81, 71-95.

Moser-Mercer, Barbara (2005). "Remote Interpreting: Issues of multi-sensory integration in a multi-lingual task". META 50(2), 727-738.

Mouzourakis, Panayotis (1996). "Videoconferencing: techniques and challenges". Interpreting 1(1), 21-38.

Niska, Helga (ed.) (1999). "Quality Issues in Remote Interpreting”. Alberto Alvarez Lugris \& Anxo Fernandez Ocampo (eds). Anovar/Anosar estudios de traducción e interpretación. Vigo: Universidade de Vigo, vol. I, 109-121.

Pöchhacker, Franz (2004). "Introducing interpreting studies". Interpreting, 6(2), 243-248.

O’Hagan, Minaiko (1996). The Coming Industry of Teletranslation. Clevedon: Multilingual Matters Ltd.

Pointon, Tom, Uldis Ozolins \& Chris Doucouliagos (1998). TIS in Europe 1976-2001: determining the origins, size, nature \& outlook of telephone interpreting services in Europe. London/Melbourne: The Pointon Partnership/Deakin University Centre for Research and Development in Interpreting and Translation.

Selhi, Taous (2000). Interpreting on the Internet. On line at: www.aiic.net

United Nations - IAMLADP (2001). Remote interpretation - Status report. Paper submitted by ITU (IAMLADP/2001/R.12). New York: United Nations. 
1 It should be noted that the term "public service interpreting" is in wider use in the UK than "community interpreting" which is sometimes taken to mean lower level intervention by compatriots, relatives or friends.

2 See also the $I T U$ website at http://www.itu.int/home/index.html. The IAMLADP website also contains useful information. IAMLADP (International Annual Meeting on Language Arrangements, Documentation and Publications) is a working group of the UN designed to facilitate communication. See http://iamladp.org/about.htm.

3 See www.immi.gov.au/tis/how.htm.

4 See http://www.dacst.gov.za/speeches/press/mar2002/tissa launch.hm for details of TISSA, the Telephone Interpreting Service of South Africa.

5 In "Interpreting is Interpreting - or is it?" on line at www.acebo.com.

6 See http://www.kwintessential.co.uk.

7 The Association Internationale d'Interprètes de Conférence at www.aiic.net and the Joint Information Systems Committee at www.jisc.ac.uk.

8 See www.aiic.net. March-April 2000. The Code includes an interesting technical annex with more details of equipment specification. Note that you should search under "Quality" to access the articles cited here and many others.

9 For more information on teleworking and the development of telecottages and telecentres, go to the website of the Telework Association (http://www.tca.org.uk), which is the largest of its kind in Europe. See also the example of the Canadian Telework Association at www.ivc.ca/ .

10 See www.nhslothian.scot.nhs.uk/outofhours/content/new_ooh.html. NHS24 is a public health enquiry line (08454 2424 24). See http://www.nhs24.com/html/content/default.asp. Translations are offered in Cantonese, Punjabi and Urdu, though there is no direct reference to interpreting services on the home page.

11 The Australian TIS has a special record for 'no parties willing to pay'.

12 See www.foreignword.com/Translators/assoc/associations.htm for a comprehensive list.

13 See http://www.languageline.com/home.php.

14 See http://www.lsaweb.com/index.php.

15 See 1-800 Translate, which operates in 157 languages. See www.1-800-translate.com/AboutUs.

16 See http://www.najit.org/examfaqs.html.

17 See www.naati.com.au.

18 For a very detailed survey of standards of practice for interpreters around the world, go to http://www.ncihc.org/NCIHC_PDF/TCE01202005_TheInterpretersWorldTour.pdf. This project was funded by the Commonwealth Fund and the California Endowment.

19 From the Independent Registration Panel for British Sign Language/English Interpreters. C/o CACDP, Durham University Science Park, Block 4, Stockton Road, Durham DH1 3UZ, England.

20 "Languages on the Front Line", The Linguist 2003, 42, 3, 84-88; "Emotional Days in Kosovo", ibid. 2003, 42, 4, 100-101; and "How I survived in Afghanistan", ibid. 42, 5, 154-155.

21 See www.ttig.org/home.html. Such links may be perfectly logical in a local context: the Translators 'Association in Britain is actually located within the Society of Authors as befits literary translators.

22 See www.najit.org.

23 See http://www.naati.com.au/fact_sheets.htm.

24 Chartered Institute of Linguists www.iol.org.uk; QCA www.qca.org.uk.

25 See www.languageline.com/prod_serv._llu.php.

26 See www.todaytranslations.com.

27 China Satcom. See http://www.chinasatcom.com/English/about.htm

28 A full list of articles by Mikkelson is to be found at www.acebo.com. Of particular interest in this context are: "Interpreting is Interpreting - or is it?"; "Plus ça change: the Impact of Globalization and Technology on Translator/Interpreter Education" and "The Court Interpreter as Protector of Defendant Rights" (both undated). 